\title{
Aproximación al manejo de la patología micótica en el pie
}

\section{Approach to the management of fungal infection in the foot}

\author{
Daniel López López ${ }^{1}$, David Rodríguez Sanz ${ }^{2}$, Angel Morales Ponce ${ }^{3}$, \\ Alfredo Soriano Medrano ${ }^{4}$
}
${ }^{1}$ Doctor por la Universidade da Coruña. Profesor Colaborador. Departamento de Ciencias da Saúde. Facultad de Enfermería y Podología. Universidade da Coruña. daniellopez@udc.es
${ }^{2}$ Doctor por la Universidad Rey Juan Carlos. Profesor Universidad Europea de Madrid. davidrodriguezsanz@hotmail.com
${ }^{3}$ Doctor por la Universidad Rey Juan Carlos. Clínica Podológica Torrijos, Toledo, España. clinicatorrijos@gmail.com
${ }^{4}$ Doctor por la Universidad Rey Juan Carlos. Clinisalud Centro Médico, Albacete, España. clinicatorrijos@gmail.com

Correspondencia:

Dr Daniel López López

Universidade da Coruña. Campus Universitario de Esteiro $\mathrm{s} / \mathrm{n}$

Departamento de Ciencias da Saúde. Facultad de Enfermaría e Podoloxía

15403 Ferrol (A Coruña)

Correo electrónico: daniellopez@udc.es

Fecha de recepción: 9 de marzo de 2013

Fecha de aceptación: 21 de junio de 2013

Los autores declaran no tener ningún tipo de interés económico o comercial.

\section{RESUMEN}

El término micosis engloba a las patologías causadas por hongos en el ser humano. Por su prevalencia, en la actualidad, se puede afirmar, que se ha llegado a comparar, a la caries dental y a los resfriados, debido sin duda alguna al alto porcentaje de pacientes que la padecen. Además, de que estudios epidemiológicos recientes, han demostrado que a parte de alterar per se la calidad de vida, (relaciones personales, nivel psicológico, deambulación...) También, pueden dar lugar a complicaciones poco deseables, provocando cuadros infecciosos y bacterianos, que suponen un alto gasto sociosanitario al ocasionar perturbación ocupacional, deterioro psicológico y físico, y una potencial estigmatización social.

La carencia de consenso en relación a la etiología multifactorial que presenta esta afección y la prevalencia de esta enfermedad a nivel del pie, sobre todo en los jóvenes y en los deportistas, nos lleva a mejorar los conocimientos existentes en lo que se refiere a su clasificación, diagnóstico y tratamiento en la búsqueda de actualizar los conceptos relacionados con esta patología del pie.

Palabras clave: onicomicosis; tiña pedis; micosis; infección podal.

\section{ABSTRACT}

The term encompasses fungal fungal diseases in humans. Because of its prevalence, today, we can say, that has been compared to dental caries and colds due undoubtedly to the high percentage of patients with the disease. Moreover, that recent epidemiological studies have shown that part per se alter the quality of life (personal, psychological level, walking...) also may result in undesirable complications, causing infectious diseases, and bacterial, involving high expenditure by causing disruption socio occupational psychological and physical deterioration, and potential social stigmatization.

The lack of consensus regarding the multifactorial etiology has this condition and the prevalence of this disease at foot level, especially in the young and in athletes, leads us to improve existing knowledge in regard to classification diagnosis and treatment in the quest to update the concepts related to this foot disorders.

Keywords: onychomycoses; dyes pedis; mycoses; podal infection.

Sumario: 1. Introducción. 2. Clasificación. 3. Formas clínicas. 4. Diagnóstico. 5. Tratamiento. 6. Conclusionres. Bibliografía.

Referencia normalizada: López López, D., Rodríguez Sanz, D., Morales Ponce, A., Soriano Medrano, A. Aproximación al manejo de la patología micótica en el pie. Rev. Int. Cienc. Podol. 2015; 9(1): 24-36. 


\section{INTRODUCCIÓN}

Entre todos los grupos de organismos que pueblan la superficie de la tierra, son los hongos los que tienen mayor poder de adaptación y a lo largo de la historia de la humanidad han traído grandes beneficios, pero también han provocado grandes perjuicios cuando parasitan al hombre siendo capaces de enfermarlo.

El término que aglutina a las infecciones fúngicas en el ser humano en general se denomina micosis ${ }^{1}$, siendo el pie a nivel particular un órgano de gran susceptibilidad de ser invadido, consecuencia en gran medida del estilo de vida de la sociedad actual ${ }^{2}$.

Aunque se desconoce, el número de especies de hongos existentes en el planeta, en la actualidad están identificadas alrededor de 100.000 especies, que corresponden aproximadamente al $10 \%$ de las encontradas en la naturaleza, de ellas 200 causan micosis en el ser humano, 20 causan micosis generalizadas y cutáneas y 12 micosis subcutáneas graves ${ }^{3,4}$.

Para el estudio de las infecciones causadas por hongos, se emplean distintas clasificaciones y terminologías dependiendo del texto de referencia, de ahí la conveniencia de conocer las definiciones que se emplean antes de iniciar la lectura de cualquier obra científica ${ }^{5}$.

De la misma manera también es básico entender que un mismo agente puede provocar diferentes cuadros clínicos patológicos, por lo tanto es susceptible de ser encuadrado en distintas clasificaciones.

Un ejemplo claro es la candidiosis, que provoca micosis superficiales y sistémicas, siendo la vía de contagio y el estado inmunológico del huésped el responsable de la aparición de la infección.
A lo largo de la revisión se describen las infecciones fúngicas más habituales y que tienen una mayor repercusión en el pie, excluyendo aquellas que se consideran excepcionales.

\section{CLASIFICACIÓN}

Las infecciones en el pie forman un conjunto muy amplio de cuadros clínicos de difícil pronóstico que pueden afectar a tejidos superficiales, profundos e inclusive pueden generar reacciones sistémicas.

El estudio de la patología micótica en el pie, está ligado a la a la clínica que provoca en el huésped, por lo tanto su clasificación sigue un criterio de orden topográfico de acuerdo a la profundidad de penetración, dentro de la cual se puede distinguir ${ }^{6}$ (véase Tabla 1 ).

1) Micosis superficiales o dermatomicosis: provocadas por hongos que invaden las capas superficiales de la epidermis, del pelo y de las uñas.

Además generan distintas respuestas en el huésped, lo que permite distinguir dos subtipos de infecciones fúngicas:

1.1. Micosis superficiales inflamatorias que provocan en el huésped una respuesta inmune, es el caso de las dermatofitosis o tiñas, las candidiosis superficiales e infecciones superficiales inducidas por hongos filamentosos no dermatofitos.

1.2. Micosis no inflamatorias que producen lesiones sin respuesta inmunitaria, ni inflamatoria y que incluyen diferentes trastornos como la pitiriasis versicolor y otras pitirosporosis, causadas por Pityrosporum ovale (sinónimo Malassezia furfur), la tiña negra palmar (Cla-

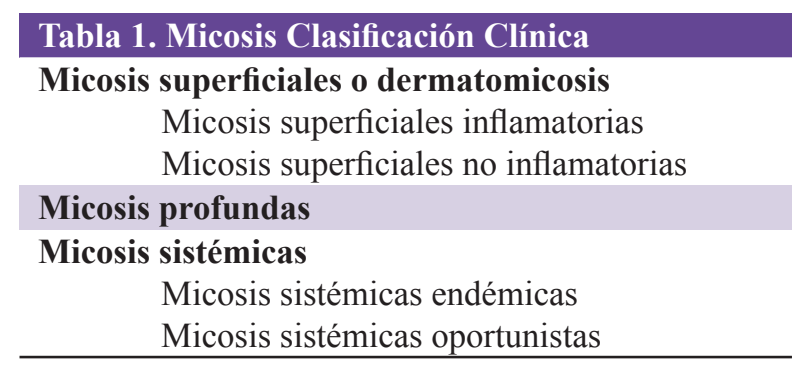

Tabla 1. Clasificación clínica de las micosis por orden topográfico. 
dosporium $=$ Exophiala werneckii $)$, la piedra negra (Piedraia hortae) y la piedra blanca (Trichosporon beigelii).

2) Micosis profundas, subcutáneas o por implantación: son afecciones inducidas por ciertos hongos saprófitos, residentes del suelo, cuyos esporos o fragmentos penetran en el huésped por implantación traumática en la piel, a través de espinas, astillas o heridas o en estructuras subyacentes que afectan a dermis, dando lugar a lesiones que asientan en la dermis y el tejido celular subcutáneo.

La condición de poseer una temperatura inferior a la de los tejidos profundos, hace de éste un lugar ideal para el desarrollo de varias especies de hongos. Estos originan lesiones crónicas que evolucionan por meses o años, y están ampliamente distribuidos en la naturaleza, principalmente en el suelo, vegetales en descomposición, madera, etc., y en regiones tropicales y subtropicales ${ }^{7}$.

La micosis subcutáneas que pertenecen a este grupo y los agentes implicados son la esporotricosis (Sporothrix schenckii), cromoblastomicosis, micetomas, eumicóticos, actinomicóticos (Actinomices).

Las patologías que provocan son lesiones en la piel de tipo nodular, placas, lesiones verrugosas, abscesos y que habitualmente tienen una escasa repercusión en el pie.

3) Micosis sistémicas: son enfermedades producidas por hongos dimórficos, que viven saprofíticamente, en forma de hongo filamentoso, en áreas geográficas definidas, típica de países tropicales y que afectan a tejidos del interior del organismo.

En ocasiones, se produce una diseminación hematógena, provocando infecciones de difícil diagnóstico, resistentes al tratamiento y de pronóstico grave.

Se distinguen dos subtipos:

3.1 Micosis sistémicas endémicas la puerta de entrada, es a través de una herida, pudiendo provocar abscesos que destruye los tejidos, o a través de las vías aéreas, infección pulmonar lenta y crónica.

Las micosis sistémicas que pertenecen a este grupo, así como los agentes patógenos más usuales son las Histoplasmosis (Histoplasma capsulatum), las Paracoccidioidomicosis (Paracoccidioides brasiliensis), los coccidioidomicosis (Coccidioides inmitis) y las Blastomicosis (Blastomyces dermatitidis) ${ }^{8}$.

3.2 Micosis sistémicas oportunistas producidas por hongos saprófitos del ambiente o comensales del cuerpo humano.

La presencia de huéspedes inmunodeprimidos y con cuadros clínicos relacionados con trastornos endócrinos, inmunodeficiencias, enfermedades oncohematológicas, alteraciones metabólicas y anatómicas, drogadictos endovenosos, pacientes bajo tratamiento prolongado con corticoides o citostáticos, sometidos a cirugía, dializados, quemados, trasplantados y cateterizados son los grupos con una mayor predisposición a ser invadidos por los hongos y presentar cuadros patológicos como la candidiasis, aspergilosis, criptococosis y mucormicosis ${ }^{9}$.

Además, ambos subtipos causan infecciones cuando se ponen en contacto con el ser humano en concentraciones importantes.

La mayoría de veces se adquieren por inhalación y el pulmón es el órgano diana, aunque se pueden ver afectados otros órganos, evidenciándose además del compromiso pulmonar, manifestaciones a nivel cutáneo y distintas formas clínicas dependiendo del estado inmune del paciente.

\section{FORMAS CLÍNICAS}

Las manifestaciones clínicas de presentación son diversas y dependen del área anatómica afectada y de la especie implicada en la infección.

Por lo tanto clínicamente, para su análisis se suele utilizar la palabra latina tinea seguida de la zona del cuerpo afectada (ej: tinea capitis si la infección afecta al cuero cabelludo).

Así mismo, un individuo puede estar infectado por una o varias especies de hongos y en varias áreas anatómicas correspondiendo cada foco infeccioso a una inoculación local.

Las manifestaciones clínicas de presentación en los pies que podemos encontrar son $^{10}$ (véase Tabla 2).

1) Tinea Pedis infección más habitual de la planta del pie y de sus áreas adyacentes pro- 


\title{
Tabla 2. Manifestaciones clínicas en el pie.
}

\author{
Tinea Pedis \\ Tinea pedis interdigital. \\ Tinea Pedis en Mocasín. \\ Tinea Pedis Vesiculosa.
}

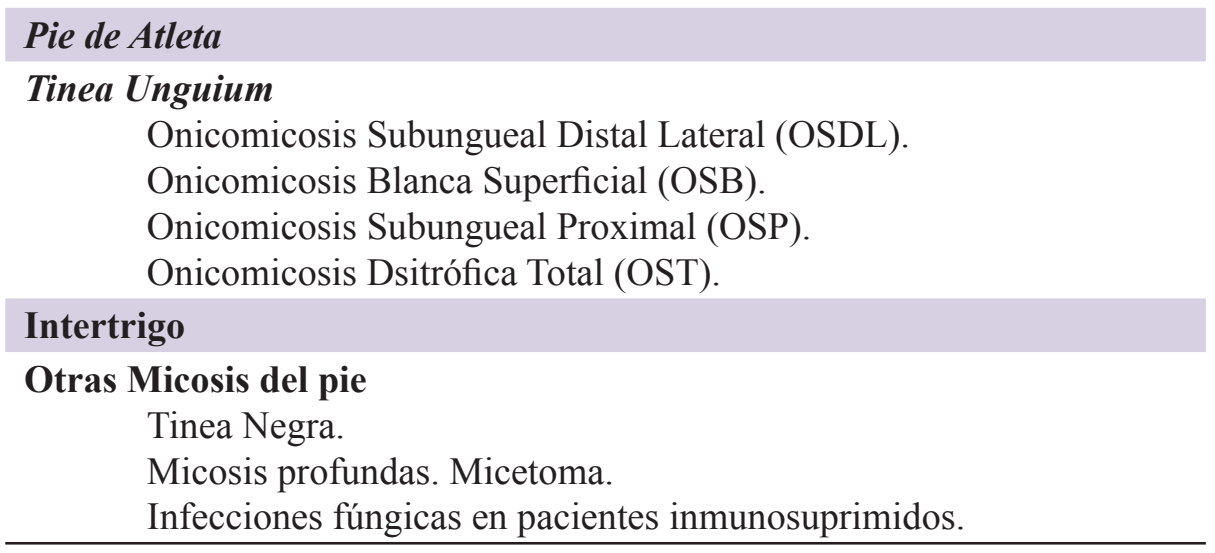

Tabla 2. Manifestaciones clínicas en el pie.

\section{Tabla 3. Formas clínicas de presentación de la Tinea Pedis}

Forma Clínica

\begin{tabular}{lll} 
Tinea Pedis Interdigital & $\begin{array}{l}\text { vesículas, eritema, prurito, } \\
\text { maceración en } 3^{\circ}, 4^{\circ} \text { y } 5^{\circ}\end{array}$ & $\begin{array}{l}\text { Trichophyton Mentagrophytes } \\
\text { var. interdigtale y } \\
\text { Epidermophyton floccosum. }\end{array}$ \\
Tinea Pedis en Mocasín & $\begin{array}{l}\text { descamación blanco } \\
\text {-grisácea, base eritematosa y } \\
\text { distribución irregular por la } \\
\text { planta del pie. }\end{array}$ & Trichophyton Rubrum. \\
Tinea Pedis Vesiculosa & $\begin{array}{l}\text { placas redondeadas y } \\
\text { preferencia por arcos } \\
\text { plantares del pie. }\end{array}$ & Trichophyton Mentagrophytes \\
\hline
\end{tabular}

Tabla 3. Formas clínicas de la Tinea Pedis.

vocadas por hongos dermatofitos. Afecta sobre todo a adultos entre los 20 y los 50 años, con predominio en varones ${ }^{6}$.

La infección suele adquirirse por deambular descalzos en baños, en duchas o en los gimnasios. Sin embargo, como en la Tinea unguium que suele acompañarla, hay una predisposición familiar con transmisión autosómica dominante, en particular para las infecciones por Trichophyton rubrum ${ }^{11}$.
Se caracteriza por aparición de prurito, descamación, maceración de la piel, erosiones interdigitales.

Recordar que este término solo incluye las infecciones provocadas por hongos dermatofíticos, aunque con frecuencia este término ha sido empleado como sinónimo para todas las micosis del pie, así como infecciones mixtas ${ }^{10}$.

Esta dermatofitosis suele presentar tres formas clínicas (véase Tabla 3). 
1.1. Tinea Pedis Interdigital es la más habitual, siendo su localización prevalente a nivel del $4^{\circ}$ espacio, que permite su diseminación al resto de pliegues interdigitales.

Los agentes causales son el Trichophyton Mentagrophytes var. Interdigtale, siendo menos habitual la presencia del Epidermophyton floccosum.

Las características clínicas están ligadas a la aparición de eritema, prurito, maceración de color blanquecino, quemazón y vesículas en $3^{\circ}$, $4^{\circ}$ y $5^{\circ}$ dedo (véase Figuras 1,2 y 3 ).

1.2. Tinea pedis crónica, hiperqueratósica o en mocasín el área de localización de las lesiones suele coincidir con la planta del pie y su agente causal es el Trichophyton. Rubrum.

Las características clínicas se relacionan con la presencia de una piel rugosa, seca y con una descamación blanco - grisácea, con base erite- matosa y de distribución irregular por toda la planta del pie.

En ocasiones suele ir acompañada de un ligero enrojecimiento, aunque no existe sintomatología, suele ser crónica y de difícil tratamiento (véase Figuras 4 y 5).

1.3. Tinea pedis dishidrosiforme, vesiculosa, vesículoampollosa o ampollosa caracterizada por la aparición de placas más o menos redondeadas con preferencia por los arcos plantares y tendencia a invadir zonas laterales y dorsales próximas, siendo su agente causal el Trichophyton Mentagrophytes.

De la misma manera, se puede manifestar en el arco interno del pie y en el pulpejo de los dedos en forma de vesículas, que cuando se desbridan o rompen, tienen una tonalidad translúcida que al secarse generan mucho prurito y dolor.
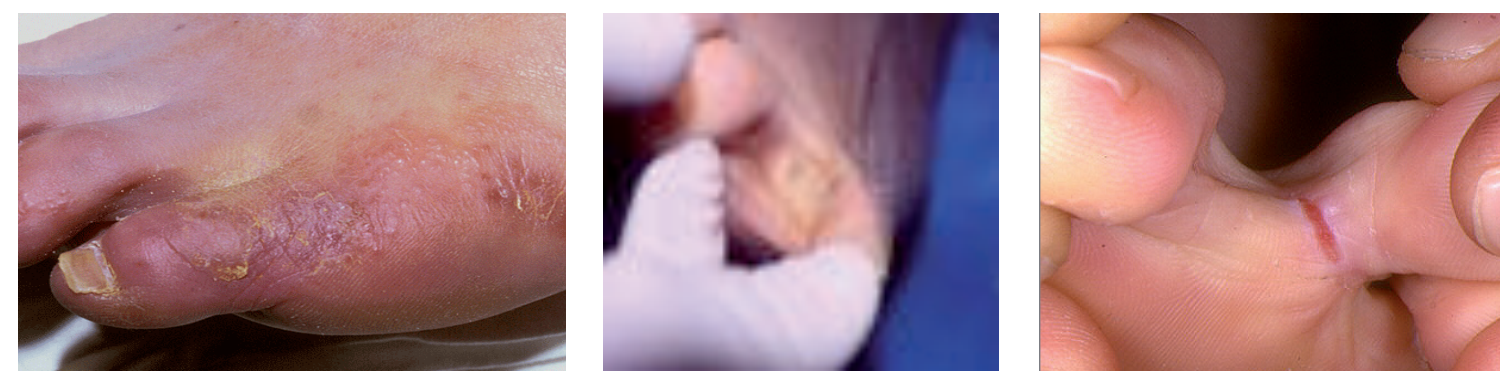

Figuras 1, 2 y 3. Presentaciones clínicas de la Tinea Pedis Interdigital.
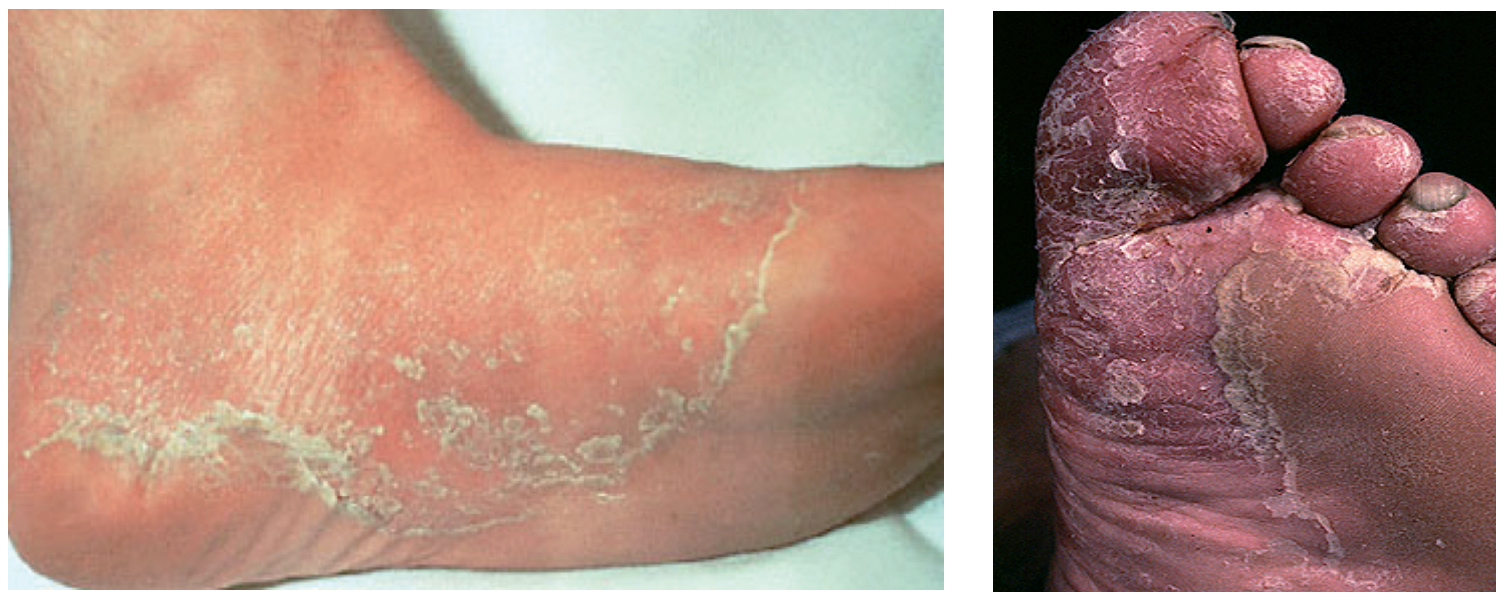

Figuras 4 y 5. Presentaciones clínicas de la Tinea pedis crónica. 

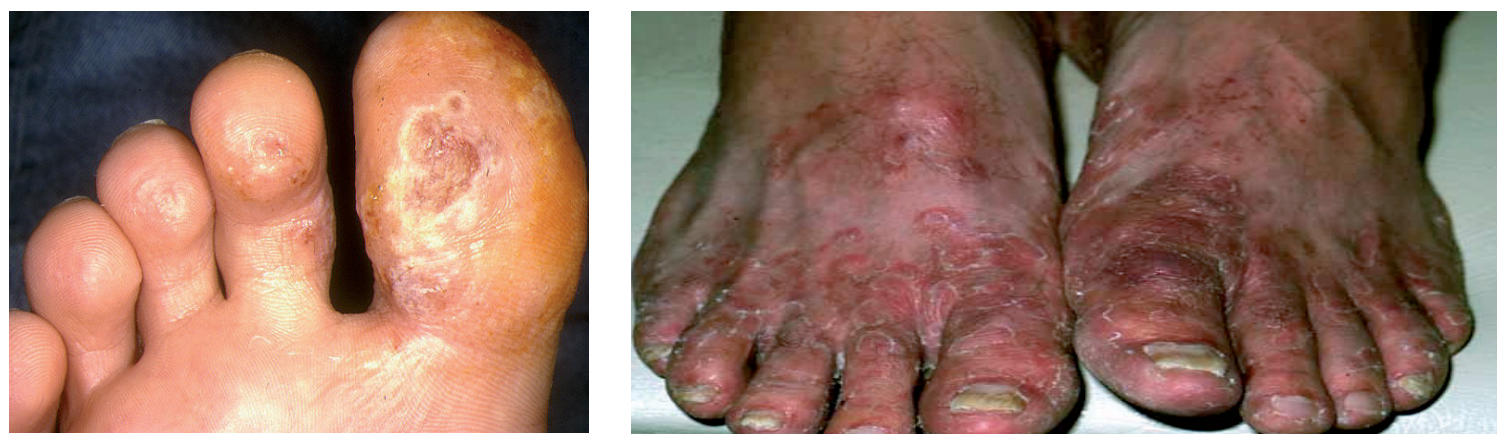

Figuras 6 y 7. Presentaciones clínicas de la Tinea Pedis vesiculosa.
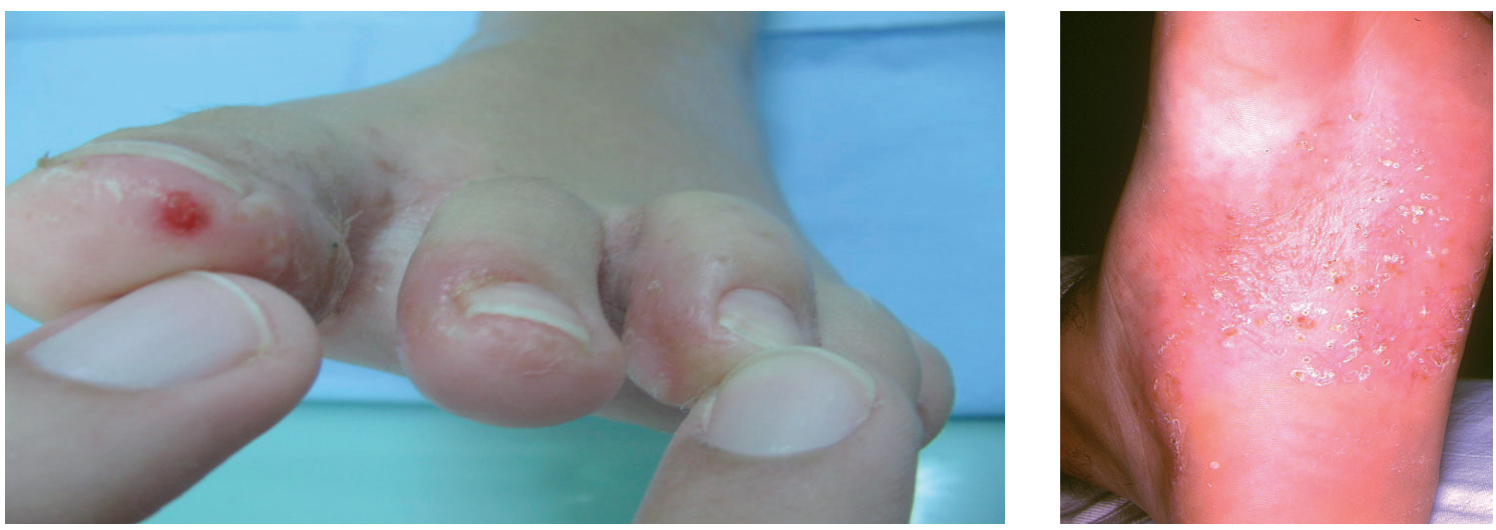

Figuras 8 y 9. Presentaciones clínicas de Pie de atleta.

2) Pie de atleta término que engloba a las infecciones provocadas en los pies por cándidas, dermatofitos, mohos y bacterias como los Sthaphylococcus, Corynebacterium o microorganismos Gram negativos.

En ocasiones su forma de presentación es mixta, coexistiendo diferentes agentes.

La clínica es muy similar a la Tinea pedis, caracterizada por presentar lesiones vesiculares acompañadas de prurito, dolor, así como lesiones eritematosas y descamativas que suelen ser crónicas y recurrentes (véase Figuras 8 у 9 ).

3) Tinea Unguium infección del aparato ungueal provocada por hongos dermatofitos, mohos y levaduras a través de tres vías: hiponiquio, eponiquio y lámina ungueal.
Así mismo, las condiciones que facilitan la aparición de esta infección ungueal se relacionan con la utilización de calzado estrecho que impide la transpiración del pie, acompañado de microtraumatismos repetitivos, de enfermedades vasculares o déficit del sistema inmune.

Según Baran, Hay, Tosti y Haneke (12), las onicomicosis pueden clasificarse en cinco formas clínicas (véase Tabla 4).

3.1 Onicomicosis Subungueal Disto-Lateral es la forma clínica más común y habitualmente el agente causal es el Trichophyton Rubrum.

La infección comienza en el borde libre y los laterales de la parte ventral de la uña (hiponiquio), donde se aprecia un cambio de color en a lámina ungueal, la cual se torna en esa zona amarilla y/o marronácea, el lecho ungueal con- 


\section{Tabla 4. Formas clínicas de presentación de las Tineas Unguium}

Forma Clínica

\section{Onicomicosis Subungueal Hiperqueratosis subungueal \\ Distal Lateral (OSDL) y decoloración amarillenta - parduzca.}

Onicomicosis Blanca Manchas blancas en forma radial. Trichophyton interdigtale Superficial (OSB)
Trichophyton Rubrum.
Agentes causales

$\begin{array}{cll}\begin{array}{c}\text { Onicomicosis Subungueal } \\ \text { Proximal (OSP) }\end{array} & \begin{array}{l}\text { Hiperqueratosis, leuconiquia, } \\ \text { onicólisis. }\end{array} & \text { Trichophyton Rubrum. } \\ \begin{array}{c}\text { Onicomicosis Dsitrófica } \\ \text { Total (OST) }\end{array} & \text { Uñas afectadas en su totalidad } & \begin{array}{l}\text { Trichophyton spp y } \\ \text { levaduras }\end{array}\end{array}$

\begin{tabular}{cll}
$\begin{array}{c}\text { Onicomicosis Endonix } \\
(\mathrm{OE})\end{array}$ & $\begin{array}{l}\text { Onicólisis, hiperqueratosis y } \\
\text { presencia de manchas blancas e } \\
\text { indentaciones transversales. }\end{array}$ & $\begin{array}{l}\text { Trichophyton tonsurans } \\
\text { Trichophyton violaceum }\end{array}$ \\
\hline
\end{tabular}

Tabla 4. Formas clínicas de la Tinea Unguium.
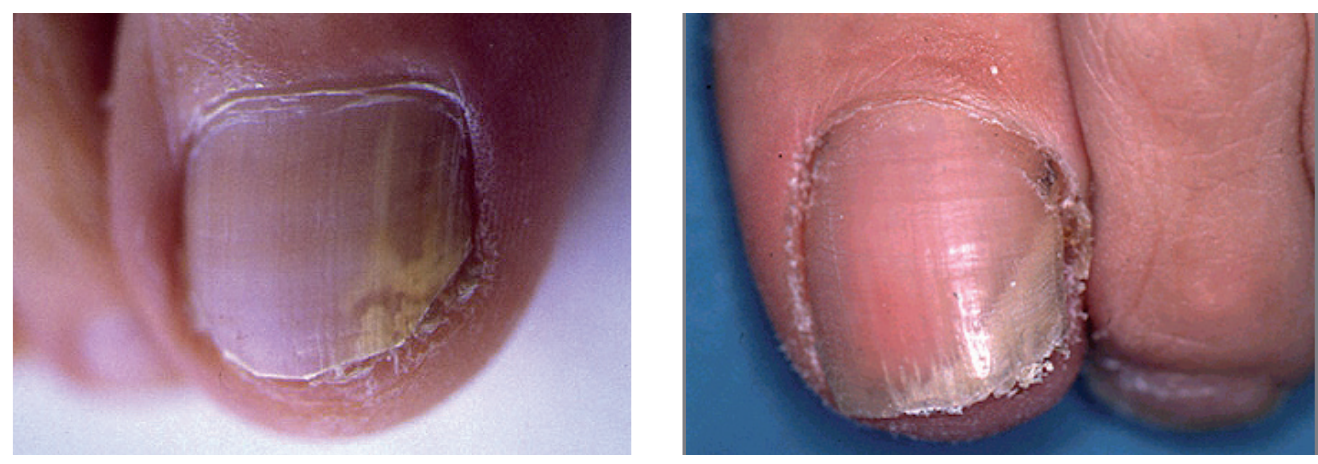

Figuras 10 y 11. Presentaciones clínicas de las Onicomicosis subungueal disto-lateral.
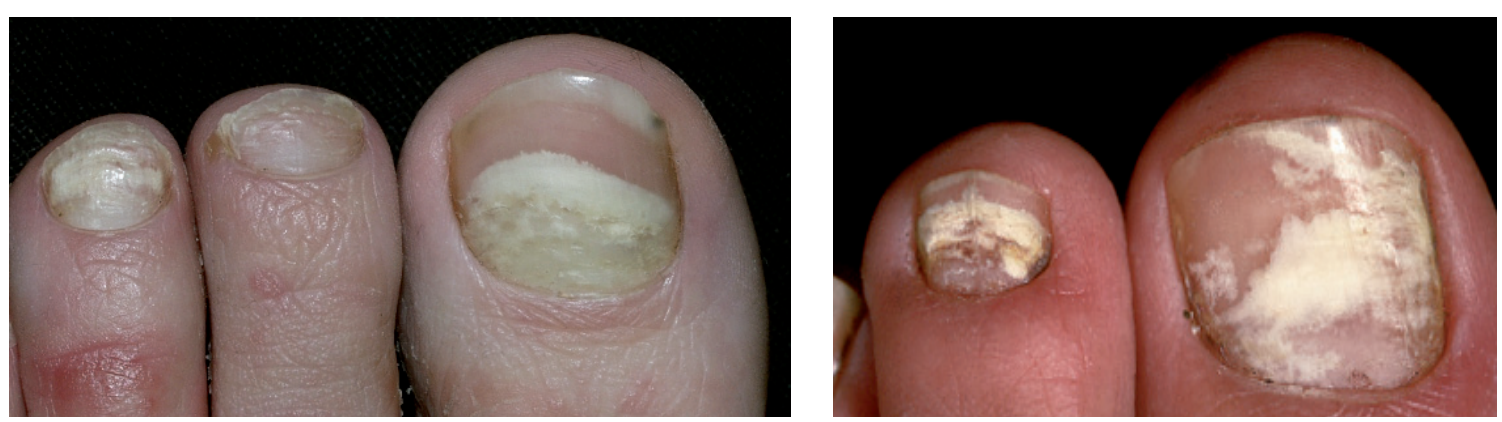

Figuras 12 y 13. Presentaciones clínicas de las Onicomicosis blanca superficial. 
tiene hiperqueratosis y la uña es quebradiza (véase Figuras 10 y 11).

3.2. Onicomicosis Blanca Superficial invasión dorsal de la lámina ungueal.

La infección comienza por la superficie dorsal de la placa de la uña, presentando un aspecto blanquecino siendo el agente causal habitual los dermatofitos y afectando principalmente a la tercera y cuarta uña de los pies (véase Figuras 12 y 13$)$.

3.3. Onicomicosis Subungueal Proximal afectación de la cutícula, por microtraumatismos o utilización de instrumental contaminado.

La uña comienza a ser invadida por la parte proximal (lúnula) y el margen proximal de la uña aparece sobreelevado existiendo inflamación local. El germen causal son las levaduras o los dermatofitos (véase Figuras 14 y 15).

3.4. Onicomicosis Distrófica Total es la forma más severa de afectación ungueal estando infectada en su totalidad.

Cualquiera de estas formas citadas con anterioridad, puede progresar, a través de varios estadíos hasta está infección total.

La clínica está relacionada con la presencia de hiperqueratosis subungueal, cambio de coloración, llegando a una destrucción total de la misma. Es usual, la existencia de distintas entidades que facilitan la existencia de la lesión (véase Figuras 14 y 15).
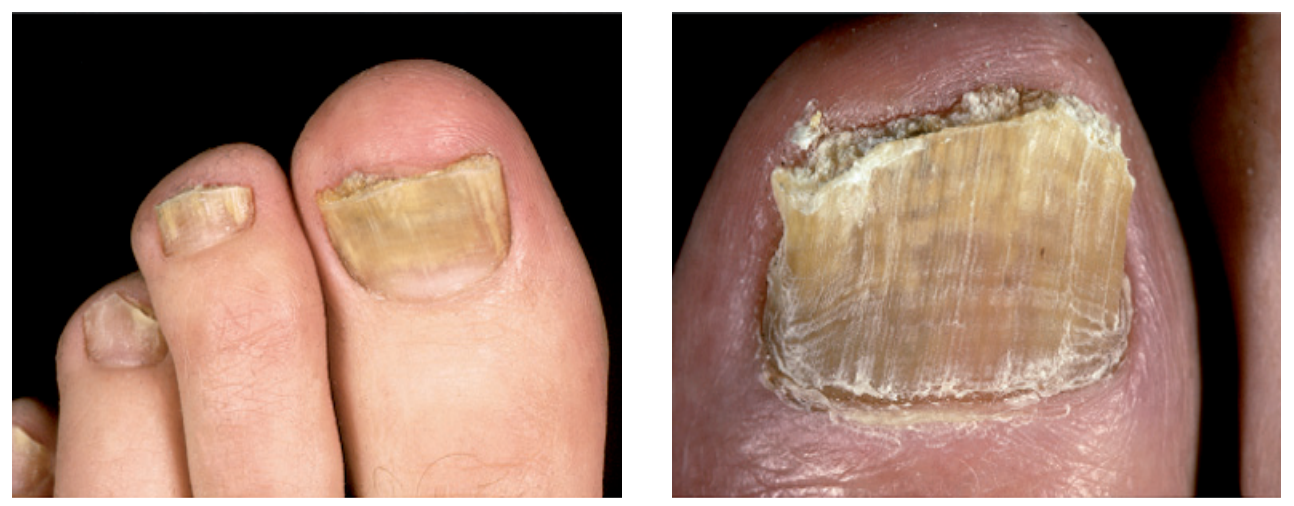

Figuras 14 y 15. Presentaciones clínicas de las Onicomicosis Subungueal Proximal.
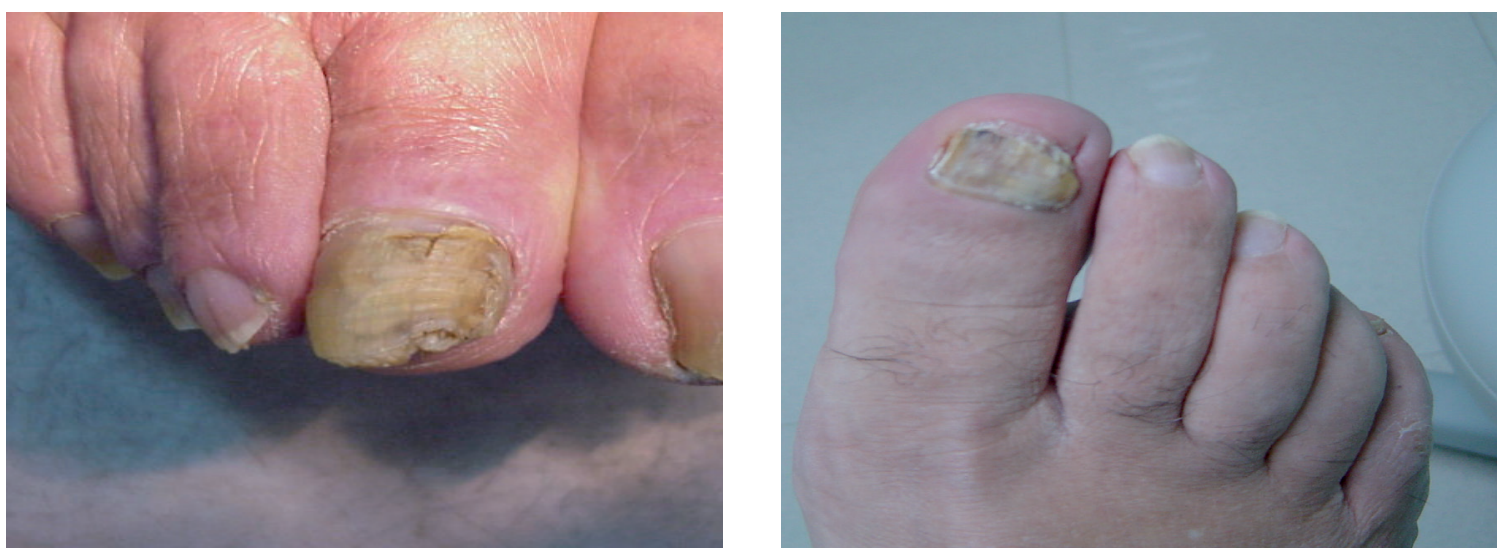

Figuras 16 y 17. Presentaciones clínicas de las Onicomicosis Subungueal Proximal. 

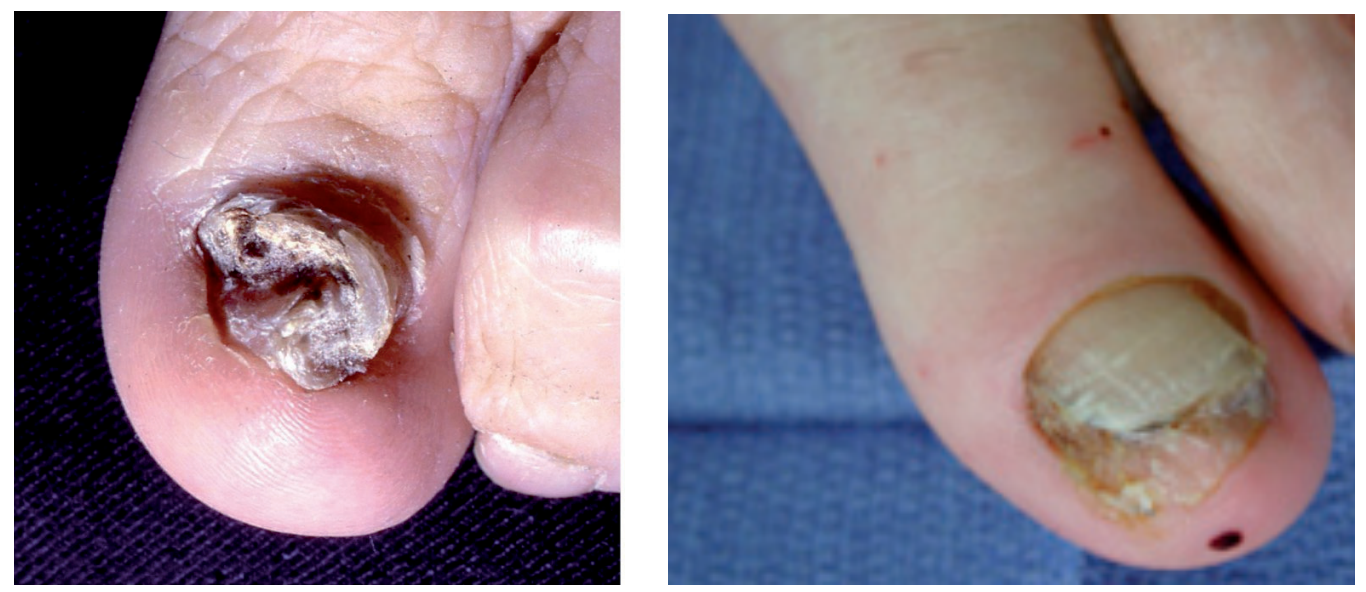

Figuras 18 y 19. Presentaciones clínicas de las Onicomicosis Subungueal Proximal.
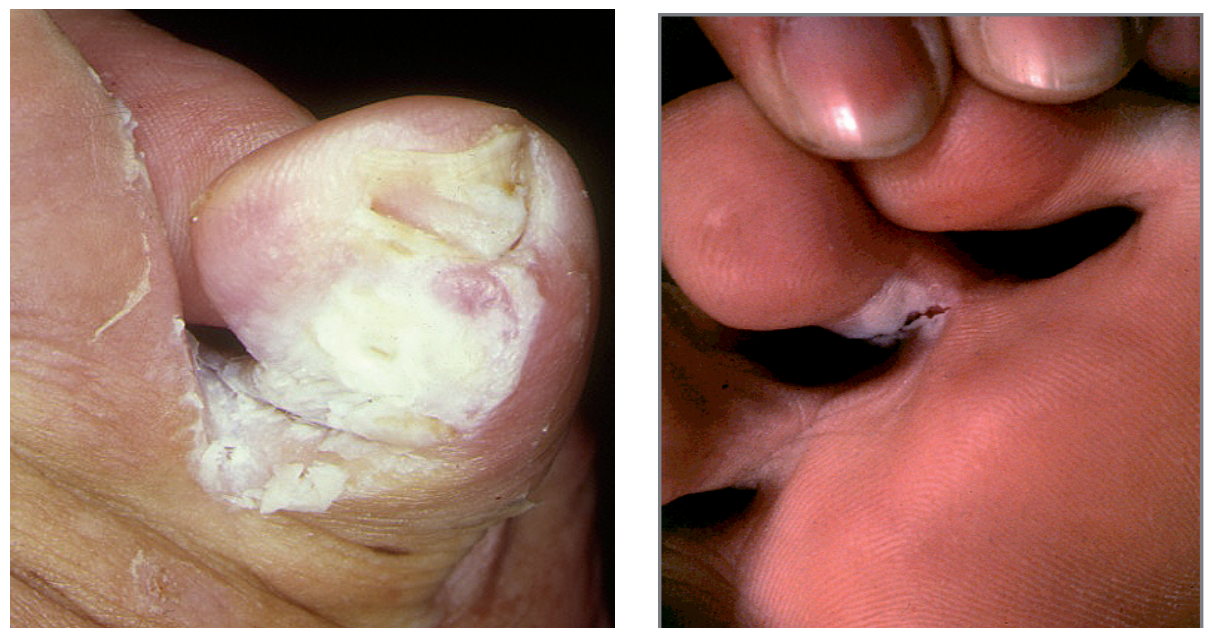

Figuras 20 y 21. Presentaciones clínicas del Intertrigo.

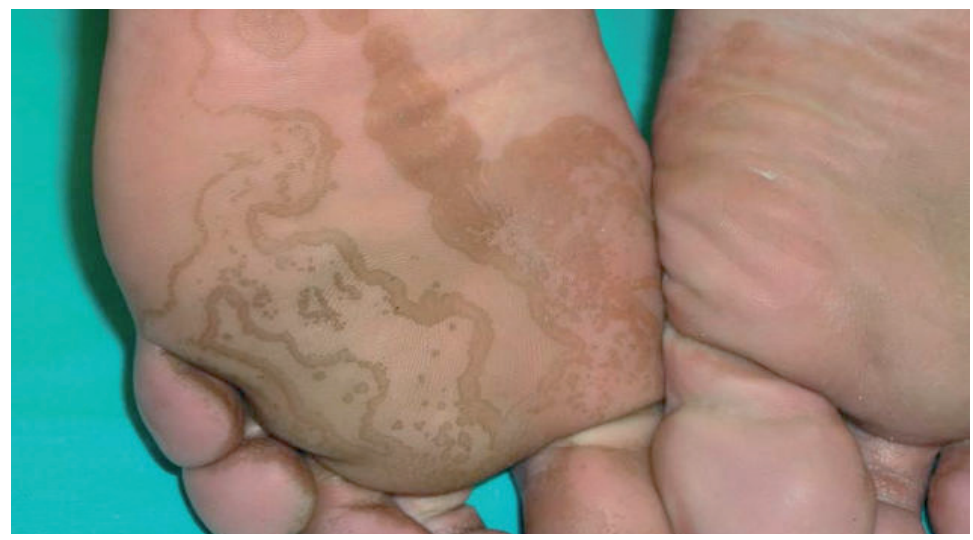

Figura 22. Tinea Negra (véase Martínez, Gómez Valcarcel, \& Crespo-Erchiga, 2007). 
3.5. Onicomicosis Endonix asociada a infecciones del cuero cabelludo causadas por los dermatofitos.

La infección comienza por la zona superficial de la uña e invade las capas profundas de la placa ungueal (véase Figuras 18 y 19).

4) Intértrigo afectación de la piel que rodea a la uña, siendo única y descamativa, habitualmente a nivel del $5^{\circ}$ dedo del pie y del pliegue interdigital del $4^{\circ}$ espacio.

Los agentes causales de esta infección del aparato ungueal son los hongos dermatofitos, los mohos y las levaduras, siendo la cándida el germen más habitual (véase Figuras 20 y 21).

La clínica está asociada a un cuadro de tipo eritematoso, edematoso y acompañado de bastante dolor.

\section{5) Otras micosis del pie:}

5.1. Tinea Negra es una dermatomicosis superficial común en zonas tropicales y subtropicales, como las del Caribe, Sudamérica, África y Asia aunque también existen casos en Europa y los Estados Unidos.

El agente causal es el hongo levaduriforme hifomicete dematiaceo Phaeoannellomyces (Exophiala werneckii), hongo altamente pleomórfico, no sólo por su presentación parasitaria sino también por su aspecto macro y microscópico en su estado saprofito, motivo por el cual ha sido sistematizado en varios géneros como Ladosporium werneckii, Aerobasidium werneckii, Exophiala werneckii y últimamente como Phaeoannellomyces werneckii ${ }^{13}$.

En cuanto a las manifestaciones clínicas, se aprecia la presencia de máculas negruzcas hiperpigmentadas circunscritas de diferentes tonalidades que van del marrón al negro y sin signos inflamatorios, generalmente indoloras y no pruriginosas. Ocasionalmente puede haber prurito, con descamación leve o ausente, siendo el aspecto estético el motivo principal de la consulta (véase Figura 22).

5.2. Micetoma es una infección micótica profunda crónica, inflamatoria progresiva y granulomatosa prevalente a nivel del pie.

El germen causal es muy variable siendo los más habituales los subgrupos del micetoma actinomicotico y maduromicótico junto a la presencia de otras bacterias como los Sta- phylococcus aureus, Pseudomonas aeruginosa (Botriomicosis) $^{14}$, que está presentes en el suelo y que pueden entrar al tejido subcutáneo por inoculación traumática.

Las características clínicas se relacionan con múltiples nódulos, los cuales supuran y drenan a través de senos, descargando granos durante la fase activa de la enfermedad.

\section{DIAGNÓSTICO}

La concreción etiológica de cualquier patología en general y en el pie en particular, es un proceso secuencial fundamentado $\mathrm{en}^{2}$ :

1) Anamnesis o historia clínica el objetivo principal está orientado a recabar información sobre el motivo de consulta que manifiesta el paciente y que se relaciona de manera subjetiva con la sintomatología que presenta y de forma objetiva los con signos clínicos de la enfermedad (tumoración, lesión cutánea, distrofia ungueal....).

Los aportes relacionados con antecedentes personales (enfermedades de base, intervenciones quirúrgicas), hábitos cotidianos (higiene personal, actividades complementarias, calzado), actividad laboral, pueden contribuir al establecimiento del diagnóstico.

2) Exploración física del pie relacionada con la inspección de la zona en busca de lesiones descamativas, heridas, úlceras, erosiones, cambios de color de la piel.

Además, la palpación de pulsos arteriales, toma de temperatura, sensibilidad, valoración de rangos articulares, prominencias óseas, morfología ungueal nos permite recabar información del proceso en cuestión.

Del mismo modo la exploración tiene que incluir la palpación del dolor (óseo, a la presión compatible con osteomielitis), crepitación (indicativo de infección por gas), tumefacción y otros signos indicativos de infección.

3) Pruebas complementarias o diagnósticas permiten confirmar el diagnóstico formulado con los datos obtenidos en la anamnesis y en la exploración física.

De esta manera, para Pemán, Martín y Rubio $^{15}$ son de gran utilidad: 
3.1. Examen clínico mediante luz de Wood permite diferenciar la presencia de enfermedades fúngicas y observar la existencia de pequeñas lesiones descamativas en los márgenes de la lesión.

Además, diferentes microrganismos no fúngicos en presencia de la luz de Wood van a adquirir una tonalidad fluorescente determinante para su identificación.

Así, la infección por Corynebacterium minutissimun responsable del Eritrasma (uno de los principales diagnósticos diferenciales de la tinea pedis interdigital), produce a la observación mediante la luz de Wood, una fluorescencia de color rosa coral.

En el caso del Trychophytom mentagrophytes var. interdigitale, produce una fluorescencia de color verdoso a la observación mediante la luz de Wood.

3.2. Examen microscópico directo es el medio simple, rápido y económico de detección de infecciones fúngicas ${ }^{16}$.

Cuando los elementos fúngicos están presentes en número suficiente se puede establecer una orientación diagnóstica presuntiva, en ocasiones definitiva, y en pocos minutos informar al clínico, lo cual permitirá la instauración temprana de una terapia antifúngica.

La técnica consiste en recolectar material del fondo de la lesión o del techo de la misma, ayudado de una hoja de bisturí del número $15 \mathrm{y}$ proceder a su posterior transporte por medio de una placa de petri o bastoncillo (véase Figuras 25 y 26).

A continuación se deposita en un portaobjetos donde se le añade una solución de KHO al $20-30 \%$ con tinta Parker que se deja actuar durante unos minutos o se acelera con calor durante algunos segundos.

El examen al microscopio de luz óptica nos permite identificar la existencia o no de los elementos fúngicos, ya que el hidróxido de potasio disuelve la queratina y las hifas se pueden visualizar mejor.

3.3. Cultivo es el único método que permite confirmar el diagnóstico e identificar el agente causal.

El procedimiento consiste en recolectar material del fondo de la lesión o techo, mediante una hoja de bisturí del número 15 o gubia y su posterior almacenamiento en una placa de petri o bastoncillo.

A continuación se deposita en una placa de petri de $90 \mathrm{~mm}$ y se incuba durante un periodo aproximado de 21 días a una temperatura de unos $25-28^{\circ} \mathrm{C}$ en agar Sabouraud glucosa (AGS) o en agar-urea.

La presencia de colonias aisladas y las características morfológicas de coloración y el examen microscópico permite identificar el agente etiológico.

3.4. Otras pruebas complementarias de gran interés, cuando aparecen resultados negativos o poco significativos $\operatorname{son}^{2}$ :
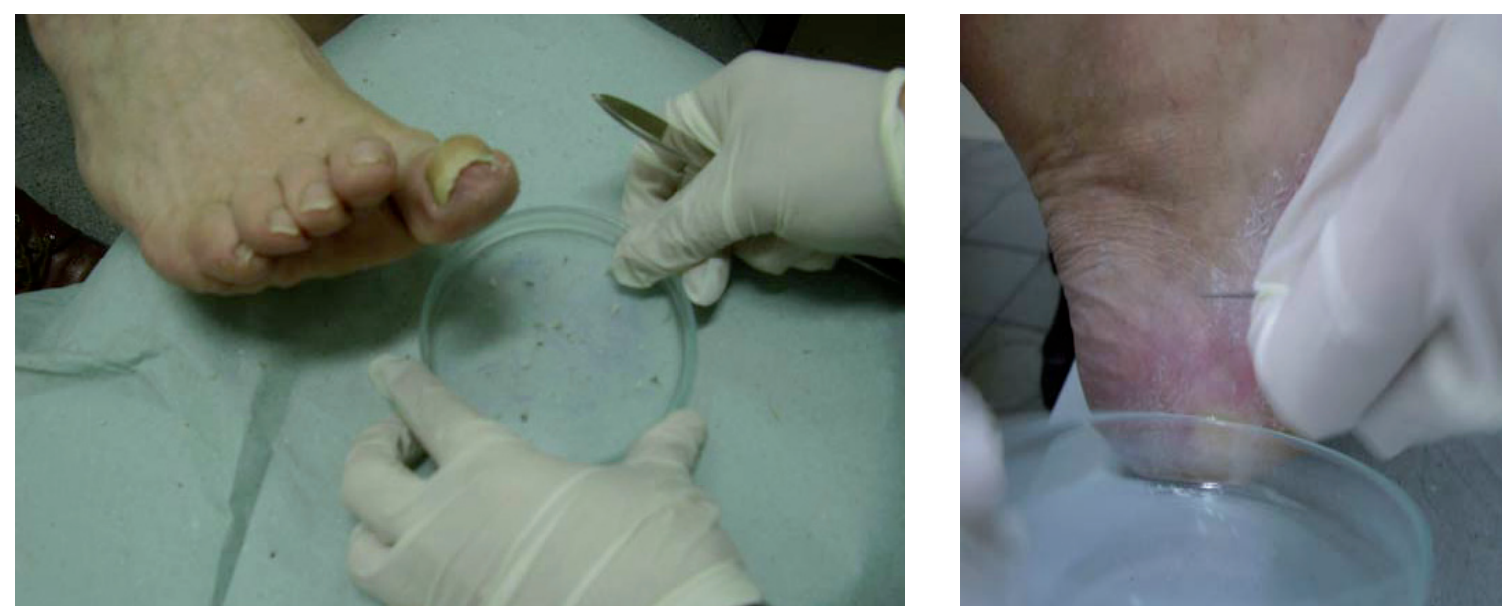

Figuras 25 y 26. Recogida en placa de petri de material de la lesión. 
3.4.1 Analítica general que incluya los parámetros bioquímicos $\mathrm{y}$ hematológicos básicos que permiten orientarnos al diagnóstico de osteomielitis o artritis.

3.4.2 Técnicas de imagen como son la radiología simple (RX), tomografía axial computerizada (TAC), resonancia magnética nuclear $(\mathrm{RMN})$, gammagrafía ósea $(\mathrm{GO})$, que nos informa de la localización del proceso.

3.4.3 Técnicas anatomopatológicas permiten detectar los cambios histológicos producidos por el agente patógeno y los ocasionados por la respuesta del huésped a la infección (la extensión de la lesión) y además puede ayudar a reconocer en los tejidos los microorganismos causales de diversas infecciones.

Las muestras para estudio anatomopatológico se obtienen a partir de biopsia parcial o completa de la lesión, citología, punción aspiración con aguja fina (PAAF), o extirpación quirúrgica (Ej. avulsión parcial o total de la lámina ungueal).

La observación microscópica de las muestras preparadas permite demostrar la presencia de microorganismos invadiendo los tejidos.

\section{TRATAMIENTO}

En la medida de lo posible, el tratamiento de la patología fúngica debe ser de tipo etiológico, conociendo el agente responsable y modificando aquellas conductas de riesgo (calzado oclusivo, caminar descalzo, falta de higiene y de hidratación de la piel) que son favorecedoras de la presencia del agente causal.

Aunque en ocasiones se realiza un tratamiento empírico en función del cuadro clínico, siendo la pauta farmacológica muy variable, dependiendo mucho de la zona de asentamiento de la lesión y del las condiciones orgánicas del paciente.

El podólogo debe decidir que antifúngico debe prescribir en función de la situación clínica del paciente, de la farmacocinética del antifúngico y sus posibles efectos adversos, existiendo tres vías de actuación:
1) Terapia tópica (veáse tabla 5) es la más habitual en estadíos inciales, agudos y en aéreas bien delimitadas, aunque la monoterapia tópica es inefectiva en infecciones extensas y recurrentes ${ }^{17,18,19}$.

2) Terapia oral (véase tabla 6) de gran utilidad en entidades como la onicomicosis, la $t i-$ nea pedis o en caso de micosis extensas y en aquellas situaciones donde el tratamiento tópico es ineficaz ${ }^{20}$.

3) Terapias combinadas ofrecen sin dudarlo los mejores resultados, siempre y cuando el diagnóstico haya sido correcto, aunque debe evaluarse la relación beneficio/riesgo ${ }^{1}$.

Por un lado, el tratamiento tópico (amorolfina, imidazólicos, naftifina, ciclopiroxolamina, terbinafina...) erradica los hongos en la piel o en lámina ungueal y el tratamiento oral (imidazólicos, terbinafina...), puede tratar la piel y / o el lecho ungueal.

De la misma manera es importante no aplicar cremas con corticoides, porque enmascaran la lesión y generan múltiples recidivas.

\section{CONCLUSIONES}

Las micosis en el pie es una patología habitual con gran repercusión en la sociedad actual y consecuencias clínicas, siendo la presentación clínica variable, así como los patrones de distribución, la severidad e impacto en las personas.

La variedad de opciones de tratamiento disponibles se deben enfocar en función de la gravedad y al agente causal de la infección que facilita en la mayoría de los casos, la adaptación del tratamiento a cada paciente en la búsqueda de un resultado satisfactorio donde se ha tener en cuenta otros factores como la duración del efecto, los efectos secundarios, las complicaciones, el coste económico, así como la adherencia terapéutica del paciente, relacionada con la toma de decisiones en el abordaje terapéutico. 


\section{BIBLIOGRAFÍA}

1. Foster KW, Mahmoud A, Ghannoum MA. Epidemiologic surveillance of cutaneous fungal infection in the United States from 1999 to 2002. J Am Acad Dermatol, 2004, 50, 748-52.

2. Alou L, Becerro de Bengoa R, Sevillano D, Prieto J, Maestre JR.. Infecciones en el pie. Manejo de la enfermedad. Madrid: Dismann, 2005.

3. Zapata L. (2000). Epidemiología de las micosis superficiales. Dermatología Perúana, 2009, 19(3): 223-266.

4. Rueda R. Micosis superficiales y dermatomicosis Revista Colombia Médica, 2002, 33(1): 10-16.

5. Fonseca E. Concepto y clasificación. En JJ.Vilalta (eds). Micosis cutáneas (pp 29-36). Madrid : Panamericana, 2005.

6. Crespo - Erchiga V, Martínez S, Martínez L. Micosis Superficiales. En JJ Vilalta (eds). Micosis superficiales (583-608). Madrid : Panamericana, 2008.

7. Negroni R, Arechavala A. Generalidades. En JA Basualdo, CE Coto, RA, de Torres (eds). Microbiología biomédica (pp 441-453). Buenos Aires: Atlante, 1996.

8. Patterson TF. Infections Caused by Dimorphic Fungi. En W. Kelley. Textbook of Internal Medicine (eds). Infectious Diseases and AIDS. Philadelphia: Lippincott Williams \& Wilkins, 1998.

9. Edwards JE. Opportunistic Fungal Infections. En W. Kelley (eds). Textbook of Internal Medicine. Philadelphia: Lippincott Williams \& Wilkins, 1998.

10. Almagro M, Maestre JR, Maestre C. Infecciones fúngicas en el pie. En J. Prieto., JR Maestre (eds). Manual de Infecciones en el pie (233-246). Madrid: Mileto, 2003.

11. Zaias N, Tosti A, Rebell G, Morelli R, Bardazzi F, Bieley H. Autosomal dominant pattern of distal subungual onychomycosis caused by Trichophyton rubrum. J Am Acad Dermatol, 1996, 34: 302-304.

12. Baran R, Hay, RJ, Tosti A, Haneke, E. A new classification of onychomycosis. Br. J. Dermatol, 1998, 139: 567-571.

13. Tucto S, Castillo W, Téllez, ML. Tiña negra palma reporte de dos casos. Dermatología Perúana, 2002, 12: $227-23$.

14. Villa AM, Castro C. Micetoma. CES Medicina, 2008, 22: 71-78.

15. Pemán J, Martín E, Rubio MC. Guía práctica de identificación y diagnóstico en Micología Clínica. Revista Iberoamericana de Micología, 2006.

16. Fernández D, Carmona FJ. Dermatomicosis. Revista Sesiones Clínicas Podológicas, 2003, 1: 1-6.

17. Jain S, Sehgal VN. Itraconazole versus terbinafine in the management of onychomycosis: an overview. Journal of Dermatological Treatment, 2003, 14: 30-42.

18. Pereiro M, García-Martínez FJ, Alonso-González J. Actualización en el tratamiento de las micosis cutáneas. Actas. Dermosifiliogr, 2012; 103 (9): 778-783.

19. Crawford F, Hollis S. Topical treatments for fungal infections of the skin and nails of the foot..Cochrane Database of Systematic Reviews 2007, Issue 3. Art. No.: CD001434. DOI: 10.1002/14651858. CD001434.pub2

20. Bell-Syer SEM, Hart R, Crawford F, Torgerson DJ, TyrrellW, Russell I. Oral treatments for fungal infections of the skin of the foot.. Cochrane Database of Systematic Reviews 2002, Issue 2. Art. No.: CD003584. DOI: 10.1002/14651858.CD003584. 